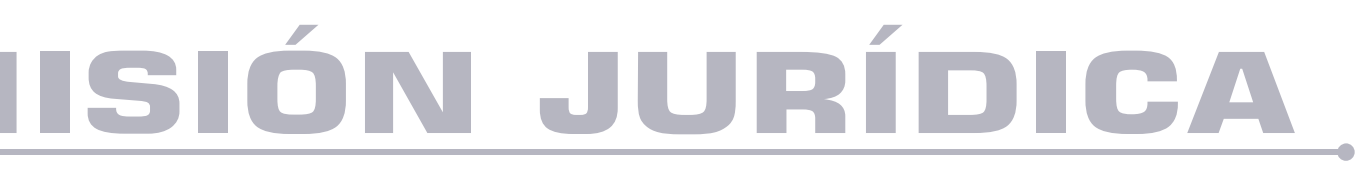

Noción de intimidad sexual desde la jurisprudencia de la Corte Constitucional colombiana

The concept of sexual privacy in the jurisprudence of the colombian Constitutional court

Autor: Alexander Fula López

DOI: https://doi.org/10.25058/1794600X.996

\footnotetext{
SP MISIÓN JURÍDICA A 


\section{NOCIÓN DE INTIMIDAD SEXUAL DESDE LA JURISPRUDENCIA DE LA CORTE CONSTITUCIONAL COLOMBIANA*}

\author{
THE CONCEPT OF SEXUAL PRIVACY IN \\ THE JURISPRUDENCE OF THE COLOMBIAN \\ CONSTITUTIONAL COURT
}

\section{RESUMEN}

Para entender cuál es el alcance y el significado de los derechos sexuales y reproductivos en las cárceles de Colombia, es necesario encontrar elementos para hilvanar la discusión sobre la categoría de intimidad que, desde la jurisprudencia de la Corte Constitucional es imprescindible para la preservación de la dignidad de los privados de la libertad. Desde el análisis de esta categoría, pueden destacarse las primeras nociones de los derechos objeto de estudio. En este artículo se intenta develar que las tensiones para la garantía de tales derechos surgen por la no existencia de una teoría clara sobre los mismos, y una disposición de trabajar en la posibilidad de que las particularidades posibilitan la construcción de unas condiciones que posibilitan el ejercicio de los Derechos Sexuales y Reproductivos en Colombia.

\footnotetext{
* Artículo de investigación científica que presenta análisis de información recolectada para la Tesis Doctoral en Derecho titulada "Los Derechos Sexuales y Reproductivos en las Cárceles de Colombia", para la Universidad del Rosario.

a. Politólogo de la Universidad Nacional de Colombia, estudios en Maestría en Estudios Políticos y Relaciones Internacionales en el IEPRI, de la Universidad Nacional, Doctorando de la Universidad del Rosario. Docente e Investigador de la Universidad Colegio Mayor de Cundinamarca y Universidad Militar. Universidad Del Rosario Facultad de Jurisprudencia Doctorado en Derecho.
}

\author{
Alexander Fula López ${ }^{a}$ \\ afulal@unicolmayor.edu.co
}

Fecha de recepción: diciembre 03 de 2018 Fecha de revisión: febrero 14 de 2019 Fecha de aceptación: abril 07 de 2019 xual desde la jurisprudencia de la Corte

Constitucional colombiana. Revista

Misión Jurídica, 12, (16), 313 - 323. 


\section{PALABRAS CLAVES}

Derechos Sexuales y Reproductivos; Intimidad; Cárceles.

\begin{abstract}
To find elements for a real understanding of Sexual and Reproductive Rights in Colombian jails analytical tools are necessary to begin to disentangle the discussion on the category of Intimacy that in the Colombian Contitutional Court is noted as essential in the preservation of the dignity of individuals deprived of liberty. From the study of this notion the first notions of the rights that are being analysed can be pointed out; this article is an attempt to reveal that the tensions on the assurance of this type of rights develop because of the lack of a clear theory on the matter and a disposition to work on the posibility that the particularities make possible the construction of conditions that make the exercise of Sexual and Reprodutive Rights in Colombia feasible.
\end{abstract}

\section{KEY WORDS}

Sexual and Reproductive Rights; Privacy; jails.

\section{RESUMO}

Encontrar elementos para compreender o alcance e o significado dos direitos sexuais e reprodutivos nas prisões da Colômbia, é necessário para começar a encadear a discussão sobre a categoria de privacidade, que a partir da jurisprudência do Tribunal Constitucional é essencial para a preservação da dignidade das pessoas privadas de liberdade. A partir da análise desta categoria, as primeiras noções dos direitos em estudo podem ser destacadas. Neste artigo procuramos revelar que as tensões pela garantia de tais direitos decorrem da falta de uma teoria clara sobre elas, e uma disposição para trabalhar em que as particularidades permitam a construção de condições que permitam o exercício de direitos, direitos sexuais e reprodutivos na Colômbia.

\section{PALAVRAS-CHAVE}

Direitos sexuais e reprodutivos; intimidade; prisões.

\section{INTRODUCCIÓN}

El objetivo de este artículo es hacer un recorrido por la noción de intimidad, expresión que es un elemento transversal de una investigación sobre los Derechos Sexuales y Reproductivos (en adelante DSR) en las cárceles de Colombia. La afirmación que se intentará sustentar en este escrito es que la intimidad, como concepto jurídico, es abierta e imprecisa con el fin de construir, sustentar y permitir posiciones y significados desde aplicaciones particulares. Los elementos que ayudarán a reflexionar sobre esta afirmación son: (i) precisar la noción de intimidad construida desde el material jurídico colombiano, y (ii) revisar aspectos teóricos y prácticos que determinan las formas o métodos para la construcción del concepto. Estas últimas son el control de convencionalidad y la acción de tutela.

La intimidad significa para el diccionario de la Real Academia de la Lengua: "1. Amistad íntima. 2. Zona espiritual íntima y reservada de una persona o de un grupo, especialmente de una familia" (RAE, 2019). Obviamente tales definiciones son limitadas para el tema propuesto, puesto que identificar intimidad con el tema de la actividad sexual es de primer plano una arbitrariedad necesaria y metodológica para esta investigación, y de entrada podría proponerse que la sexualidad es solo la unión de lo biológico, lo social, lo sicológico y lo cultural, cuando tiene que ver con el comportamiento, las actitudes y los sentimientos de la persona; formando parte fundamental de la personalidad del individuo orientada por la razón, la voluntad y las demás dimensiones y valores del ser humano.

El momento en el cual la pareja se encuentra para disfrutar de su otro en una relación sexual que puede ser penetrativas o no. Entendidas las primeras como: Las relaciones sexuales penetrativas incluyen además de besos, abrazos y caricias contacto genital (pene vagina, pene - ano, pene - boca) o penetración con otro tipo de elementos u objetos. Y las no penetrativas que incluyen caricias, besos, abrazos y masturbación, entre otras actividades, sin llegar a la penetración. Esta aseveración que utiliza y distingue Profamilia, de entrada, es útil para empezar a dialogar al respecto (https:// profamilia.org.co).

A partir de lo anterior y en aras de la investigación, es necesario confirmar que, en los primeros acercamientos a las fuentes de 
información en la Cárcel Nacional Modelo, la noción de DSR es básicamente nula dentro de los discursos y diálogos establecidos con los internos y parte del personal a cargo de la prisión, siendo las herramientas más cercanas para los internos: (i) el derecho a la visita conyugal, (ii) el cuidado de las enfermedades por contagio sexual y el (iii) derecho al beso que negocian los miembros de la comunidad LGBTI, es claro entonces que la noción de intimidad aparece tenuemente.

Este diálogo no es solo entre disciplinas, es una construcción de sentido jurídico que alimenta el universo de condiciones y elementos que precisan una investigación que intenta descubrir ¿cómo las normas tocan el cuerpo de manera efectiva? o para ser precisos ¿cómo las normas, sin importar su origen y su efectividad, logran condicionar este aspecto del desarrollo del sujeto? Condicionar significaría entonces, que la norma ubica comportamientos en la persona y en su actividad sexual que le somete a una relativa libertad en su desarrollo, en este caso aquellos privados de la libertad.

\section{ANTECEDENTES A LA NOCIÓN DE INTIMIDAD}

El término "intimidad", al rastrearse como categoría de análisis, se puede ubicar en disciplinas como la antropología, la psicología, el psicoanálisis y el derecho. No significa esto que no haya más posibilidades disciplinares, sino que estas disciplinas acusan un esfuerzo visible que se puede identificar en un trabajo preciso que delimitará al plano jurídico colombiano.

Como punto de partida las sentencias de la Corte Constitucional colombiana se convierten en un insumo que determinan cómo las normas jurídicas dan sentido al desarrollo de la experiencia sexual en las cárceles colombianas, que conectan con el desarrollo de los derechos sexuales y reproductivos.

Para el jurista colombiano Edgar Escobar (2004) la piedra angular donde se ha sustentado la inserción del concepto de "intimidad" al ámbito jurídico nace en la expresión "tener derecho a ser dejado en paz" emitida presuntamente por el juez Cooley de los Estados Unidos, pero allí precisamente en 1890 el magistrado del Tribunal Supremo, Louis Brandeis, quien a la par de Samuel Warren escribieron un texto reprochando la invasión a la intimidad sufrida por Warren cometida por un periodista. En 1939 Nizer refiere que el "derecho a la intimidad es el derecho del individuo a una vida retirada y anónima" (Escobar, 2004: 36-37) William Swuindier afirma que el derecho a la Vida Privada es aquel "derecho a vivir su propia vida en soledad, sin ser sometido a una publicidad que no se ha provocado ni deseado" (Escobar 2004: 37). Posteriormente Lucier Martin dice que "la vida privada es la vida familiar, personal del hombre, su vida interior, espiritual, la que lleva cuando vive detrás de su puerta cerrada". Su ubicación codificada se postula en que la obra "Derecho Civil" de Jean Carbonnier sostiene que "la intimidad es la esfera secreta de la vida del individuo en la que tiene el poder legal de evitar a los demás". (Escobar 2004: 37).

En este instante es útil referir a Cass Sunstein (2006) en su texto "Acuerdos Carentes de una Teoría Completa en Derecho Constitucional y Otros Ensayos". La tesis del autor consiste en que "la gente se pone de acuerdo sobre prácticas constitucionales, y hasta sobre derechos constitucionales, cuando no puede ponerse de acuerdo sobre teorías constitucionales (...) ordenamientos constitucionales que funcionan bien tratan de resolver problemas a través de acuerdos carentes de una teoría completa" (p.35). Las premisas que dan contenido y sentido a dicha sugerencia son: (i) los acuerdos permiten abstracciones que son aceptadas y desacuerdos en las particularidades por lo tanto tal fenómeno posibilita en el derecho constitucional y en política la construcción de la Constitución. (ii) las reglas y las analogías son enunciadas como "los dos métodos más importantes para resolver disputas constitucionales sin obtener un acuerdo sobre principios fundamentales, tales dispositivos buscan hacer posible la obtención de acuerdos donde el acuerdo sea necesario y hacer innecesaria la obtención de acuerdo donde sea imposible un acuerdo" (p. 36) (iii) premisa "con frecuencia se llega a un acuerdo carente de teoría completa sobre un principio general, queriendo decir con esto que las personas que aceptan el principio no necesitan estar de acuerdo sobre lo que implica en casos particulares" (p. 39).

Así el punto de partida es identificar las características del escenario que emerge de los acuerdos de prácticas y derechos constitucionales sin acuerdos sobre teorías constitucionales. Cass Sunstein (2010) formula esto como un fenómeno, 
donde los acuerdos permiten abstracciones que son aceptadas y desacuerdos en las particularidades, lo cual posibilita en el derecho constitucional y en política la construcción de la Constitución. Sin embargo, admite que acuerdos carentes de una teoría completa a veces incluyen resultados concretos en vez de abstracciones. A la vez el fenómeno tiene como posibilidad que ante el desacuerdo o la duda sobre una cuestión abstracta se avance hacia un nivel de mayor particularidad, es decir un descenso conceptual.

Dado lo anterior es necesario observar que la intimidad como concepto jurídico es abierto e impreciso con el fin de sustentar posiciones y significados desde particularidades así sea de manera histórica. A continuación, se hará un recorrido sobre la noción de intimidad desde el material jurídico colombiano, situación que no se da adrede sino por construcción de cultura jurídica.

La revisión propuesta por Escobar, 2004, es juzgada per se, como un conjunto de reflexiones subjetivas, sin embargo, aduce una concepción hecha por el Tribunal Superior de Bogotá donde Abelardo Rivera Llano define

la vida privada debe constituir una ciudadela donde estén protegidos y asegurados los cuatro estados característicos de la privacidad y la libertad: a) la soledad, cuando la persona vive sola por autodeterminación; b) la intimidad, cuando el individuo está en compañía de otros o de un pequeño grupo (familia, amigos); c) el anonimato, que consiste en el interés de no ser identificado en la rutina de cada día; d) la reserva, entendida como voluntad de no revelar ciertas cosas sobre sí mismo (Rivera, 1982: 17).

Tales conceptualizaciones podrían alejarse del objetivo de este trabajo, ya que no es posible identificar tales aseveraciones con la posibilidad del concepto necesario para el desarrollo de este escrito sobre la noción de intimidad dentro del espacio de lo sexual, por lo tanto encontrar el vínculo en una noción que se confunde con privacidad no es la vía, pero es lo que se ha construido manera arbitraria, la conexión fáctica se encuentra y puede empezar a rastrearse con la noción de visitas conyugales que de entrada sostiene una serie de dificultades conceptuales que se comentarán más adelante. El vínculo que le concede Escobar a la noción de intimidad lo localiza con el derecho al libre desarrollo de la personalidad y la intimidad. Refiere entonces que las personas que se encuentran privadas de la libertad (preventivamente o condenadas) tienen derecho a la visita conyugal por parte de la esposa o esposo, o del amante o compañero. Esta debe entenderse en el sentido de satisfacer los apetitos sexuales (Escobar, 2014). En cuanto al tema, las visitas a los centros de reclusión dejan claro, por parte de los directivos, que las visitas conyugales se encuentran reguladas por el reglamento interno de los centros de reclusión donde se tienen que generar las condiciones adecuadas para el desarrollo de la actividad sexual ${ }^{1}$.

Yendo a las normas jurídicas un lugar de observación primaria del material, los artículos 1, 13 y 15 de la Constitución Política Colombiana (CPC) establecen:

Artículo 1. Colombia es un Estado social de derecho, organizado en forma de República unitaria, descentralizada, con autonomía de sus entidades territoriales, democrática, participativa y pluralista, fundada en el respeto de la dignidad humana, en el trabajo y la solidaridad de las personas que la integran y en la prevalencia del interés general.

Artículo 13. Todas las personas nacen libres e iguales ante la ley, recibirán la misma protección y trato de las autoridades y gozarán de los mismos derechos, libertades y oportunidades sin ninguna discriminación por razones de sexo, raza, origen nacional o familiar, lengua, religión, opinión política o filosófica (...).

Artículo 15. Todas las personas tienen derecho a su intimidad personal y familiar y a su buen nombre, y el Estado debe respetarlos y hacerlos respetar. De igual modo, tienen derecho a conocer, actualizar y rectificar las informaciones que se hayan recogido sobre ellas en bancos de datos y en archivos de entidades públicas y privadas.

De acuerdo a lo visto con Sunstein, estos son acuerdos constitucionales abiertos e imprecisos, es necesario observar cómo en el ejercicio de la materialización del espíritu de la norma, el material

1. El hacinamiento carcelario es un factor determinante en este análisis por cuanto, según Archila y Hernández el incremento de la población carcelaria "no es correlativo con el presupuesto económico que se ha destinado para ésta. Lo anterior genera una serie de condiciones deplorables que "afectan el espacio vital, la alimentación, la salud y la seguridad de los presos"”' (2015: 202). 
jurídico del cual dota la Corte Constitucional puede dar luces tanto al concepto como a la práctica que da significado desde lo jurídico² ${ }^{2}$.

Cabe aclarar que aquellos en condición privativa de libertad, se suspenden algunos derechos como el de la libertad, a la libre circulación, derechos políticos si están en condición de condenados, a la libertad de escoger profesión y oficio. Y otros se limitan como el derecho a la intimidad, a la comunicación oral y escrita, al trabajo, a la educación. Sin embargo, derechos como a la vida, a la libertad de conciencia, al debido proceso, el derecho a invocar el hábeas corpus, se mantienen inviolables.

\section{CÁRCEL, CORTE CONSTITUCIONAL Y NOCIÓN DE INTIMIDAD}

La primera sentencia para poner en consideración es la T-596 de diciembre de 1992, de allí puede tomarse material jurídico, político y sociológico que determine objetos de investigación frente al tema carcelario, sin embargo, para el objeto de este escrito, los siguientes puntos enmarcan las condiciones de posibilidad del lugar en donde los presos construyen su estadía y con ello la posibilidad de intimidad con sus parejas. En dicha sentencia el análisis concreto afirma:

La Sala de Selección Número 7 de la Corte Constitucional decidió acumular las solicitudes de tutela T-4368, T-4486 y T-4665. Todas ellas fueron instauradas por presos de la cárcel de 'Peñas Blancas' de la ciudad de Calarcá en el departamento del Quindío, y todas ellas tienen que ver con la misma violación y la misma petición: tratos degradantes como consecuencia de la inadecuada evacuación de excretas en recintos cerrados de la penitenciaría. Los reclusos se quejan de las insoportables condiciones ambientales producidas por la ubicación de letrinas deterioradas, sin agua suficiente para la limpieza y contiguas a los sitios destinados para dormir (Corte Constitucional, 1992).

Si la situación carcelaria, vista desde el marco normativo que otorga la Constitución de

2. Al respecto Jímenez, 2008, realiza un análisis sobre la dimensión que obra en el derecho colombiano a partir de la preponderancia de los principios definidos por la Constitución y desarrollados por la Corte Constitucional.
1991, ya en 1992 aparecen acciones jurídicas representativas, teniendo la tutela como instrumento usado por los reclusos, es pertinente como objeto de estudio, entonces es pertinente también, entender el papel del lenguaje y las interpretaciones que tanto reclusos como el aparato judicial asumen como propio para dar sentido a la preservación y garantía de los derechos, es decir, también que el curso de los acontecimientos ha llevado a una discusión entre el sistema judicial colombiano y los actores relevantes, esto es la creación de un escenario de discusión e interpretación sobre lo que son los derechos tanto para los agentes que buscan su garantía como para aquellos que intentan materializarlos para su vida.

Significa esto que el tema carcelario ha encontrado una vía jurídica -la tutela- ${ }^{3}$, que sobrepasa el uso de los medios de comunicación para visibilizar las situaciones relevantes de los centros de reclusión. En pocas palabras, la vigencia de la problemática carcelaria y el uso de las posibilidades jurídicas que brinda la Constitución como herramienta de los reclusos para hacer del encerramiento un lugar medianamente digno, se evidencia en una reflexión continua de los actores relevantes sobre el tema que alimenta y transforma cualquier contenido discursivo y jurídico, en casos concretos que se convierten en material de análisis y observación para posibles eventualidades futuras. Es la suma de contenidos no acabados, pero si momentos de observación para la continua reflexión.

La Sentencia T 501 de 1994 intenta dar claridad en principio sobre los derechos del interno y con estos el derecho a la intimidad: el cumplimiento estricto de las normas establecidas dentro de un centro carcelario debe realizarse, por parte de los guardianes y el personal directivo, mediante procedimientos razonables que no atenten contra la dignidad y los derechos de los internos, esto es, evitando prácticas tales como los maltratos físicos, los tratos humillantes o los castigos desproporcionados. Ahora frente al derecho a la intimidad, este se caracteriza así:

3. Sentencia T - 474 de 2012. Una vez se ha dejado claro que la visita conyugal posee, bien el carácter de derecho fundamental, bien el de ámbito o faceta constitucionalmente protegida de los derechos al libre desarrollo de la personalidad, la intimidad personal y familiar y la intimidad del interno, resta señalar que se trata de un derecho susceptible de protección directa por vía de la acción de tutela. 
La intimidad puede en ciertas circunstancias ser limitada, pero nunca vulnerada en su núcleo esencial. Lo anterior, porque como derecho que es, no puede ser absoluta. En el caso sub examine se observa con nitidez cómo se debe adecuar la intimidad a las normas legales y reglamentarias, a las necesidades de los demás reclusos, y a la disciplina propia de un establecimiento de tal naturaleza. Todo ordenamiento jurídico debe ser adaptable a las circunstancias reales, porque lo contrario sería plasmar como deber ser lo que no puede realizarse (Corte Constitucional, 1994).

De lo anterior, el núcleo esencial es la intimidad que se precisa en el desarrollo personal y familiar. Pero tal aseveración empieza a reconocer dificultad en la materialización de los derechos, el debate entre el deber ser y la realidad de materialización de los derechos soporta la necesidad de un trabajo concertado entre las normas y las condiciones de aplicabilidad, así tal sentencia insta a que los centros carcelarios

amolden el ejercicio del derecho de intimidad a las circunstancias, sin que ello implique desconocimiento del núcleo esencial del derecho. La situación especial en que se halla el peticionario -una cárcel- hace que sea imposible que su derecho a la intimidad tenga el mismo alcance que en situaciones de plena normalidad (...) Es deseable ver a los presos en condiciones de pleno bienestar, pero ello no depende del juez de tutela (Corte Constitucional, 1994).

Dicho lo anterior, se destacan los siguientes elementos: la intimidad es sujeta al otro en la cárcel, esto es, se limita por las condiciones del entorno, no puede ser normal, es decir es una intimidad adjetivada, como anormal, el juez de tutela enuncia, dice y propone la realidad y la administración de los centros tienen la responsabilidad de garantizar las ordenes de los jueces. Sin embargo, un tema que sale a la luz es la capacidad de los centros para garantizar las posibilidades y ordenes de los jueces frente al goce de los derechos. Los reclusos tienen derechos que promueven una revisión entre el deber ser de la mirada del legislador y las condiciones reales de los centros, la distancia se hace larga y los elementos normativos se pueden ver insuficientes.
Volviendo a las conclusiones de la Sentencia T596, esta resalta:

El sufrimiento de los presos es una consecuencia inevitable, no fin en sí mismo. El sufrimiento es inseparable de la pena, pero la pena no se reduce al sufrimiento, ni lo tiene como objetivo. En consecuencia, toda aflicción excesiva y que no corresponda al fin de la pena, debe ser considerada ilegítima $\mathrm{y}$ ajena y debe ser tenida en cuenta bajo la perspectiva constitucional, con el objeto de castigar posibles violaciones de los derechos fundamentales. En el apartado 5. Toda pena, independientemente del delito del cual provenga, debe respetar unas reglas mínimas relativas al tratamiento de los reclusos, que se encuentran ligadas, de manera esencial, al concepto de dignidad humana y al principio según el cual la pena no tiene por objeto el infligir sufrimiento corporal (Corte Constitucional, 1992).

Así por lo tanto expresiones tales como: sufrimiento inseparable a la pena y pena como necesaria, útil y proporcional generan posibilidades muy abiertas de considerar el sufrimiento adecuado y proporcional, y quien se atribuye tal margen de interpretación y acción de generar dicho sufrimiento, por otra parte, la imprecisión de que la pena no tiene por objeto infligir sufrimiento corporal deja entrever que hay otro tipo de sufrimiento del cual la pena sí podría disponer. Pero como tal, permite pensar en la continua reflexión que diferentes agentes pueden hacer sobre la materialización de los derechos. Puesto en discusión la anterior sentencia y algunos temas claves allí consignados para la cuestión sobre la intimidad, existe una primera disposición que vincula esta categoría con el goce de algunos derechos ${ }^{4}$, esto es el concepto de dignidad humana que en principio la sentencia lo conecta con la imposibilidad de la pena de infligir sufrimientos corporales, por lo tanto los tratos degradantes en primera instancia se están ubicando en el cuerpo, sin embargo de entrada separar el sufrimiento entre el cuerpo y la psiquis es en principio discutible.

4. "El cambio de época que se ha venido dando hacia la categoría de víctimas, implica un cambio de idea sobre la concepción de justicia en todos los aspectos. En el derecho penal por ejemplo se comienza a dar entonces un cambio, intentando mirar hacia las víctimas y hacia su sufrimiento" (Diaz: 2012: 269). 
Posteriormente, yendo un poco más allá del tema del sufrimiento y el cuerpo, la Sentencia C-394 de 1995 admite que la intimidad tiene un carácter relativo ya que debe preponderar el régimen de disciplina y la seguridad acentuando, por lo tanto, que el administrador de tal disciplina o quien haga su vez dentro de los centros adquiere por su función poder de significar lo adecuado para respetar la razonabilidad y relatividad del derecho con adjetivos de prudencia y razonabilidad. En la sentencia citada, el tema se comprende bajo la expresión "firmeza" en los actos propios del régimen disciplinar, atribución que ejecutan los guardias en sus actos del "servicio "estos" [refiere a la guardia] deben respetar el pudor y la privacidad de los internos de manera prudente y razonable. Lo anterior significa, permitirles un mínimo de intimidad en todo aquello que no constituya amenaza contra la disciplina y la seguridad del establecimiento" (Corte Constitucional, 1995). Posteriormente enuncia esta sentencia:

-DERECHO A LA INTIMIDAD DEL INTERNO- En los establecimientos carcelarios el derecho a la intimidad no es absoluto, sino que está limitado en atención a las exigencias propias del régimen disciplinario y a las condiciones de seguridad que han de mantenerse. Las facultades de custodiar y vigilar constantemente a los internos y de requisarlos cuidadosamente son inherentes a la función de los guardianes en cualquier establecimiento de esta índole. Sin embargo, deben éstos respetar el pudor y la privacidad de los internos de manera prudente y razonable, es decir permitirles un mínimo de intimidad en todo aquello que no constituya amenaza contra la disciplina y la seguridad del establecimiento (Corte Constitucional, 1995).

Y, para finalizar, admite:

DISCIPLINA CARCELARIA. La "firmeza" de que se habla en este literal no debe traducirse en actos que constituyan violación a la norma constitucional, que prohíbe los tratos crueles, inhumanos o degradantes.

La prohibición no implica que el recluso no pueda poseer material pornográfico, porque cada persona es libre de escoger sus lecturas y pasatiempos, mientras no afecte los derechos de los demás. Cuestión distinta es que, por razones de moralidad, un servidor público no puede ser divulgador de pornografía, y ese es el sentido de la norma acusada; concretamente los miembros del cuerpo de vigilancia no pueden ser difusores de pornografía, cuando la misión de los establecimientos carcelarios es de readaptación, y no de degradación moral (Corte Constitucional, 1995).

Esta sentencia deja claro temas reflexionados en este escrito, en primera medida no hay una interpretación unívoca de los derechos y delega a las autoridades carcelarias discrecionalidad en sus actos, pero con un marco de acción. Este marco es una trilogía entre derecho a la intimidad, relatividad del mismo y firmeza, que de entrada le dice a la administración carcelaria desde dónde obrar y reflexionar. Sea esto prudente o apropiado no es objeto de este escrito, solo se define que, sin criterios claros, cualquier interpretación puede ser objeto de revisión y validez. Un ejemplo como el de la pornografía donde la sentencia deja claro que, quienes deciden si un acto define peligro a la disciplina del establecimiento o degradación moral es la misma guardia en primer momento. ¿Qué significaría esto dentro de un centro de reclusión? Esto es objeto de otro trabajo, pero podría adelantarse la existencia de un control subjetivo de quienes detentan el poder sobre la intimidad de los reclusos a través de una relación entre "derecho a la intimidad, relatividad del mismo y firmeza", ya que la amplitud en la reflexión y en los desacuerdos desde la teoría sobre el derecho a la intimidad que se construye desde acciones judiciales en el caso de Colombia, posibilita en el campo de acción que otros elementos sociológicos, entre ellos el poder, decida lo que es o no adecuado en el curso de los acontecimientos y la cotidianidad, a lo cual existirá una respuesta de los internos o un modelo de negociación de sus intereses frente a lo que pueda darse como un acto jurídico, que permitirá un nuevo momento de acción y reflexión. Un ejemplo que concretiza la observación señalada puede ser la Visita Conyugal.

\section{VISITA CONYUGAL}

Este elemento también referido indistintamente como intima en algunos apartes, aparece en la disertación sobre el espacio creado dentro de los centros carcelarios para la garantía de derechos. La Sentencia T-269/02 permite aterrizar el tema de la visita conyugal, escenario no único, pero sí delimitado donde el desarrollo 
sexual puede efectuarse de manera reglada, es decir, para efectos del trabajo investigativo la visita conyugal no se convierte en el único escenario posible para el tema de la construcción del universo sexual de los reclusos, siendo un escenario reconocido institucionalmente de entrada es necesario que la realidad sobrepase el objetivo y disposición de dicho espacio íntimo.

Desde la afirmación El respeto a la dignidad humana, pilar del ordenamiento constitucional, la persona no se puede ser sometida a limitaciones ni siquiera cuando se encuentra recluida. El derecho a la visita conyugal del interno muestra la sentencia referida como fundamental por conexidad, la visita conyugal, con derechos como la intimidad, la protección a la familia y la dignidad humana, aunque limitado por las condiciones propias del encierro, la Corte insta la necesidad de instalaciones físicas adecuadas, privacidad, higiene y seguridad.

La ausencia de tales condiciones no debe ser razón para determinar la imposibilidad del curso de dichas visitas, los centros deben propender, por lo tanto, a hacer efectivas las condiciones para el desarrollo de las visitas conyugales. Pero la corte se atreve un poco más y decide significar en la misma sentencia:

(...) la visita íntima es aquel espacio que, como su nombre lo indica, brinda a la pareja un espacio de cercanía, privacidad personal y exclusividad que no puede ser reemplazado por ningún otro. Piénsese por ejemplo en las visitas generales las cuales se realizan usualmente en un patio o locutorio acondicionado común, al cual concurren a su vez los demás reclusos. Si bien estas visitas permiten un acercamiento, no le dan a la pareja las condiciones físicas de la visita de carácter íntimo. En tal ambiente, es a todas luces complejo desarrollar el mismo grado de cercanía, intimidad y familiaridad (Corte Constitucional, 2002).

Hacer un acucioso trabajo etnográfico sería importante para responder la siguiente pregunta: ¿Qué elementos de análisis teóricos y disciplinas de estudio toma en consideración la Corte Constitucional para dar tales conceptos? Pero más aún, en la siguiente consideración se propone la pregunta anterior al decir la Corte:
Tratándose de personas privadas de la libertad, se hace esencial para los reclusos y su pareja el poder relacionarse en el ámbito sexual ya que este tipo de encuentros además de tener como sustrato un aspecto físico, trasciende al psicológico y al ser positivo repercute en el estado de bienestar de la pareja. Y la visita conyugal debe admitirse según la corte para aquellos reclusos que tengan conformada una familia como para los que no, el derecho a la visita íntima constituye un desarrollo claro del derecho al libre desarrollo de la personalidad contemplado en el artículo 16 de la Carta (Corte Constitucional, 2002).

Sin embargo, tales visitas tienen restricciones razonables explicadas por la misma corte, las cuales deben ser definidas por los administradores carcelarios usando el Juicio de Proporcionalidad 5 .

Por último, en la Sentencia T - 474/12 la Corte propone un nuevo elemento: la relación de especial sujeción. Allí la accionante alega que el INPEC, el director del establecimiento penitenciario y carcelario "El Pedregal" de Medellín y el director del establecimiento penitenciario y carcelario de Yarumal vulneran el derecho a la intimidad personal y al libre desarrollo de la personalidad cuando niegan la visita íntima entre la peticionaria y su pareja, quienes se encuentran en condiciones de privación de la libertad en diferentes municipios, situación que dificulta la posibilidad de tales encuentros por escasez de recursos económicos y físicos.

La Corte reitera que las personas privadas de la libertad tienen suspendidos algunos de sus derechos como la libertad de locomoción; otros derechos se restringen por asociación a la naturaleza de la pena y principalmente a la necesidad de preservar las condiciones de seguridad del establecimiento penitenciario; $y$, finalmente, un grupo de derechos son intocables, como el de la salud, la integridad personal y la vida. La Sentencia T - 474/12 afirma que la suspensión como la restricción se explica por

5. Los pasos para tal juicio son: (i) determinar si la medida limitativa busca una finalidad constitucional, (ii) si es adecuada respecto del fin, (iii) si es necesaria para la realización de éste lo cual implica la no existencia de una alternativa que garantice el cumplimiento del fin limitando en menor medida el derecho que se ve restringido- $y$ (iv) si es estrictamente proporcional en relación con el fin que busca ser realizado -esto implica un no sacrificio de valores y principios que tengan un mayor peso que el principio que se pretende satisfacer. 
(...) los fines que persigue el Estado y sus obligaciones de investigar y castigar las violaciones de bienes jurídicos de especial trascendencia, preservar la seguridad, y propender por la resocialización del recluso, de manera que toda suspensión o restricción de un derecho que no guarde relación directa con esos propósitos se encuentra proscrita. (Corte Constitucional, 2014)

El concepto de relaciones de sujeción especial nace y se desarrolla en Alemania durante la época de la Monarquía Constitucional. Según Ramírez (2009), se diferenciaban dos tipos de relaciones que se tejen entre los ciudadanos y la administración. La primera relación hace referencia al vínculo existente entre el Estado y el ciudadano común; mientras que la segunda relación era la generada entre el Estado y determinados colectivos que ostentaban un estatus especial. En la segunda relación aparecen la sujeción especial que se considera compuesta por un conjunto de individuos pertenecientes a colectivos (estudiantes, presos, funcionarios, militares $\mathrm{y}$ establecimientos públicos) pero lo importante es que "esta significación es la que permite definir que las personas privadas de libertad bajo este concepto, pueden limitar el ejercicio de los derechos otorgando al Estado un especial actor que considere tanto la suspensión como la restricción de los mismos" (Ramírez, 2009: 291).

Por otro lado, en la Sentencia T474 de 2012, se afirma que:

En términos simples, muchas de las obligaciones de abstención que pesan sobre las autoridades públicas para que los ciudadanos puedan gozar de sus derechos, se tornan, en el caso de las personas internas, en obligaciones positivas, pues la persona no está en condiciones de procurar por su cuenta la eficacia de sus derechos. Las obligaciones positivas del Estado frente a toda persona se preservan en cambio incólumes (Corte Constitucional, 2012)

Para la Corte Constitucional todos los derechos tienen carácter polifacético, lo que significa que poseen diversas esferas, algunas de carácter negativo o de abstención y otras de naturaleza positiva o de prestación. Por ello, la eficacia de cualquier derecho comporta costos para el Estado pero además distingue entre fundamentalidad y reconocimiento de la importancia del derecho mediante consensos de derecho positivo, jurisprudenciales, dogmáticos o del DIDH, y con la potencialidad del mismo para la realización de la dignidad humana como y exigibilidad, esto refiere a los medios o herramientas para asegurar su eficacia que estipulativamente se pueden denominar garantías ${ }^{6}$.

La Corporación en la Sentencia T - 474/12 (en análisis) precisó que las visitas íntimas a las personas privadas de la libertad constituyen un importante instrumento para garantizar la función resocializadora de la pena y la finalidad del tratamiento penitenciario. Para la Corte, el Estado

(...) debe propender por la presencia de la familia en el proceso de resocialización del interno, la cual se relaciona con otros derechos fundamentales del recluso, dentro de los que se cuenta la posibilidad de mantener comunicación oral y escrita con las personas que se encuentran fuera del penal, así como conservar una vida sexual activa, lo que a la postre permitiría una reincorporación que genere un menor traumatismo al ex-convicto (Corte Constitucional, 2012).

Más adelante admite que las dificultades administrativas o de cualquier índole no pueden impedir el desarrollo de las visitas y allí la administración carcelaria debe construir el escenario adecuado siguiendo lo regulado por la ley, expresamente en el artículo 112 del Código Penitenciario y Carcelario, que asegura que el derecho a la visita conyugal debe hacerse efectivo. Además, la Corte recuerda que el Acuerdo 11 de 1995 del Consejo Directivo del Instituto Nacional Penitenciario y Carcelario donde se expide el Reglamento General base de reglamentos internos propios de cada centro, en su artículo 29, define que esta visita íntima es por lo menos una vez al mes sobre la materialización de las condiciones del artículo 30 de dicha norma.

6. Las garantías de los derechos comprenden todos los recursos judiciales que prevé el ordenamiento para su exigencia, pero también las políticas públicas destinadas a aumentar la cobertura de los servicios públicos, los espacios de discusión democrática y la propia acción política y social de los grupos organizados de la sociedad civil.

7. Cita la Sentencia T - 474/12 - Sentencia T-894 de 2007 (M.P. Clara Inés Vargas). En este caso la Corte estudió la situación de dos personas, recluidas en diferentes centros penitenciarios, que solicitaban mediante tutela la autorización de la visita íntima. La Corte negó el amparo porque la actora no había elevado solicitud alguna al director del establecimiento carcelario donde se encontraba recluida, tal como lo exige la normatividad pertinente. Sin embargo, ordenó a esta autoridad, informar, orientar y prestar la ayuda necesaria a la peticionaria, sobre el procedimiento a seguir, con el fin de obtener el beneficio de la visita conyugal. 


\section{CONCLUSIONES}

Todo lo revisado puede constituir un espacio histórico y jurídico donde la noción de intimidad, relativa a las relaciones sexuales, no es un concepto cerrado y que el acercamiento teórico - jurídico apropiado, en el tema de los sujetos privados de la libertad no es fácilmente visible. Lo que se evidencia es un recorrido desde actos particulares que dan contenido a la experiencia regulada de lo sexual en aspectos limitados en los centros de reclusión.

Hay evidencia de un desprendimiento teórico desde el derecho de visita conyugal que desde su formulación empieza a generar dificultades teóricas para la amplitud de un derecho a la vida íntima sexual, aquí los espacios entre cónyuges se construyen como entre parejas de esposos o compañeros, dejando de lado reflexiones de género diferenciales. Lo anterior admite que la intimidad se construye desde el otro y solo en el asunto referenciado de la pornografía se evidencia la posibilidad de un sujeto íntimo sexuado.

Grandes acuerdos desde lo constitucional y desde elementos externos como las convenciones, son temas abiertos e imprecisos que desde las particularidades se permiten responder a los actores que detentan la necesidad de garantía de sus derechos, y tal imprecisión en el tema de la intimidad en el nivel sexual, muestra cómo se activan herramientas jurídicas en el ámbito nacional, como la Tutela y a nivel constitucional y supra-constitucional el control de convencionalidad para proporcionar elementos $\mathrm{y}$ reflexiones que generen sentido para la materialización de los derechos.

No son claros los lugares desde dónde el acervo jurídico colombiano habla, no se demuestran objetos investigativos a la hora de emitir conceptos que tocan la misma intimidad de los sujetos en este caso privados de la libertad, sin embargo el espacio que genera el derecho legitima a través de los procesos las alternativas discursivas de los actores que crean el sentido y desde lo que se considera acordado, derecho a la intimidad, a la dignidad, por ejemplo, emiten posibilidades de interpretación que pujan discursivamente para lograr sus fines, es decir el derecho como herramienta y fin en sí mismo. 


\section{BIBLIOGRAFÍA}

- Abaunza, C., Mendoza, M., Bustos, P., Paredes, G., Enríquez, K. \& Padilla, A. (2014). Adultos mayores privados de la libertad en Colombia. Recuperado de: http://www. urosario.edu.co/Accion-Social-SERES/ Documentos/pi-Adultos-mayores-SERES/

- Archila, J. y Hernández, M. (2015). Subrogados y hacinamiento carcelario. Respuesta del legislador del año 2014 frente a la situación carcelaria en Colombia. Misión Jurídica, 8 (9), 199-227.

- Carbonell, M. (2013). Introducción General al Control de Convencionalidad. Recuperado de: https://archivos.juridicas.unam.mx/ www/bjv/libros/7/3271/11.pdf

- Corte Constitucional. (04 de noviembre de 1994) Sentencia T-501/94. [MP. Vladimiro Naranjo Mesa]

- Corte Constitucional. (07 de septiembre de 1995) Sentencia C-394/95. [MP. Vladimiro Naranjo]

- Corte Constitucional. (18 de abril de 2002) Sentencia T-269/02. [MP. Marco Gerardo Monroy Cabra]

- Corte Constitucional. (25 de junio de 2012) Sentencia T-474/12. [MP. María Victoria Calle Correa]

- Corte I.D.H., Caso Gelman v. Uruguay, Sentencia 24 de febrero de 2011.

- Diaz, F. (2012). La justicia desde las víctimas. Misión Jurídica, 5 (5), 267-275.

- Escobar, E. (2004). El Derecho a la Intimidad. Bogotá: Doctrina y Ley Ltda.

- Goffman, E. (2004). Internados: ensayos sobre la situación social de los enfermos mentales. Buenos Aires: Amorrortu Editores.

- Jímenez, W. (2008). Entre reglas y principios. Misión Jurídica, 1 (1), 15 -50

- Kropotkine, P. (1977). Las prisiones. Barcelona: Pequeña Biblioteca

- Londoño, M. (1996). Derechos sexuales y reproductivos "los más humanos de todos los derechos. Cali: Iseder.
- Mayorga, J. (2011). Cárceles, cielo e infierno, historias de vida. Bogotá: Agencia de reporteros sin fronteras.

- Parrini, R. (2007). Panópticos y laberintos. México D.F: El colegio de México.

- Peláez, R. (2016). Estructura del Proceso Civil en el Contexto de la Oralidad (2nd ed., p. 163). Bogotá: Doctrina y Ley.

- Ramírez, M. (2009). Consideraciones a la figura jurídica de las relaciones de sujeción especial en el ámbito español. Revista Universitas, (118), 273-291.

- Ramírez, J. (1979). Curso de sociología jurídica. Bogotá: Libro del Profesional.

- Ricard, M., Bo, R., y Climent, C. (2010). Propuesta de análisis fenomenológico de los datos obtenidos en la entrevista. UT. Revista de ciencias de l'educació, 113-133.

- Rivera, A. (1982). La libertad. el derecho a la intimidad y la informática. Primer Seminario Nacional sobre informática jurídica y gestión judicial. Bogotá: Rama Judicial.

- Shifter, J. (1988). Amor de machos. San José: Alpes.

- Soriano, R. (1997). Sociología del Derecho. Barcelona: Ariel derecho.

- Sunstein, C. (2006). Acuerdos carentes de una teoría completa en derecho constitucional.

- Precedente. Revista jurídica, (-), 31-49. https://doi.org/10.18046/prec.v0.1423

- Universidad del Rosario-Instituto Rosarista de Acción Social. (2011). Desarrollo del sistema penitenciario y carcelario Colombiano entre 1995 y 2010 . Recuperado de: https://editorial.urosario.edu.co/ pageflip/acceso-abierto/desarrollo-delsistema-penitenciario.pdf

\section{- Páginas WEB}

- http://www.javeriana.edu.co/juridicas/ pub_rev/documents/11-Consideraciones a la figura_000.pdf

- http://www.profamilia.org.co/

- http://www.corteconstitucional.gov.co/ 